\title{
A presença de Luigi Pirandello e Jorge Andrade no moderno teatro brasileiro, ou como Décio de Almeida Prado enxerga-os através da lente da formação ${ }^{1}$
}

\author{
Berilo Luigi Deiró NOSELLA ${ }^{2}$ \\ Universidade Federal de Ouro Preto - UFOP
}

\begin{abstract}
Na luta contra o "velho teatro" - o teatro baseado no vedetismo, sem diretor, sem respeito ao texto dramático, sem cenários, figurinos e iluminação adequados - Décio foi uma liderança inconteste. E embora tivesse muita consciência de que exprimia um ponto de vista pessoal ao escrever sobre uma determinada peça, sabia também que suas ideias em relação ao teatro moderno eram partilhadas por muitos. Dai ter afirmado, certa vez, que "a crítica não existe autonomamente, no vario: tomada na sua totalidade, não passa de expressão de um grupo incomparavelmente maior, que inclui encenadores e intérpretes, cenógrafos e autores, todos que formam a consciência teatral da cidade."

Os três livros de crítica de Décio demonstram cabalmente o papel que ele desempenhou entre 1946 e 1968: o de formador da consciência teatral da cidade de São Paulo.
\end{abstract}

(João Roberto Faria)

Luigi Pirandello, Jorge Andrade e Décio de Almeida Prado. Três homens e uma profunda ligação com o processo histórico e ideológico de formação do teatro moderno brasileiro. Um pela sua posição de grande autor moderno da dramaturgia mundial que passou pelos nossos palcos. Outro pela posição de grande dramaturgo nacional moderno. E outro pela tarefa de analisar, difundir e criticar a "modernidade" dramatúrgica de ambos e tantos outros, criando a "massa" que une ideologicamente os outros dois, gerando uma espécie de "consciência teatral (moderna) da cidade de São Paulo" e brasileira.

E é exatamente essa "massa" que procuraremos analisar nas próximas linhas: como Décio de Almeida Prado articulou uma recepção às obras de Pirandello e Jorge Andrade em nossos palcos à luz do que chamaremos de tradição do pensamento sobre a formação nacional, gerando uma espécie de consciência da formação do teatro brasileiro moderno. Para tal nos debruçaremos sobre as obras Críticas do autor. Tal conjunto estende-se por longos anos (1941-1968) e acreditamos que é o "caldeirão" do embate riquíssimo do autor com suas ideias, formulando-as, testando-as e amadurecendo-as. Por meio deste conjunto,

\footnotetext{
${ }^{1} \mathrm{O}$ presente artigo é fruto da pesquisa de doutorado "Luigi Pirandello e Jorge Andrade entre o texto e a cena: a metateatralidade como espelho de nossa formação estético cultural moderna", defendida em 2011 na UNIRIO. A pesquisa em questão foi realizada com apoio do CNPq, Conselho Nacional de Desenvolvimento Científico e Tecnológico - Brasil e da CAPES, Coordenação de Aperfeiçoamento de Pessoal de Nível Superior - Brasil. O material aqui apresentado compunha o Capítulo III da referida tese e foi suprimido de sua versão final para publicação, pois configurava uma abertura particular e importante de novos braços de pesquisa no corpo da mesma; aqui lançamos então os primeiros passos na direção destes novos braços.

2 Professor Adjunto do Departamento de Artes Cênicas da Universidade Federal de Ouro Preto-UFOP, atuando nas áreas de História do Teatro, Teorias da Cena e Iluminação Cênica. Doutor em Artes Cênicas, História e Historiografia do Teatro, pela Universidade Federal do Estado do Rio de Janeiro- UNIRIO. Email: luigidn@terra.com.br.
} 
então, tentaremos perceber minimamente o movimento intelectual de Décio no tempo. Temos consciência de que o trabalho proposto requereria um empreendimento analítico minucioso por todo o conjunto de críticas e textos do autor, porém, aqui nos debruçaremos sobre as críticas e textos exclusivos sobre Pirandello e Jorge Andrade. Tal empreitada - por um lado restrita em sua abrangência, mas pertinente em sua especificidade - justifica-se na crença de que se Décio gerou uma espécie de "consciência teatral (moderna) brasileira" e Pirandello e Jorge Andrade (segundo o próprio Décio) são dois paradigmas fundamentais do teatro moderno, mundial e nacional, a amostragem oferecida pelo recorte é de inestimável pertinência para traçarmos alguns contornos da noção de teatro brasileiro moderno gerada na e pela tradição do pensamento sobre a formação nacional.

\section{Décio de Almeida Prado e a formação do teatro brasileiro moderno}

Sem de fato aprofundarmo-nos aqui num debate metodológico historiográfico, o que procuraremos demonstrar é como nossa historiografia mais oficial - principalmente nos trabalhos de Décio de Almeida Prado - procurou, ao olhar para nosso teatro em geral, as características de um teatro denominado "teatro moderno"; demonstrando como esse fato gerou as seguintes fissuras: primeiro um julgamento injusto de algumas manifestações teatrais do passado; segundo a crença de que existe um "teatro" modelo para todas as manifestações teatrais, e este seria o "teatro moderno". Aqui, apresenta-se a primeira fissura do pensamento de Décio sobre a Formação: a ideia de Formação do teatro nacional como busca de um nascimento do teatro nacional.

Com o texto "Entre a tragédia e o drama: Gonçalves de Magalhães" (1996, p. 1152), Décio inicia seu livro sobre o drama romântico lançando as bases do que seria compreender a formação do teatro "coincidindo com a formação da própria nacionalidade". Fica claro, já de saída, que Décio, no fundo, está atrás do nascimento do teatro brasileiro, e de fato o encontra:

\footnotetext{
Ninguém negará a Domingos José Gonçalves de Magalhães (1811-1882) no mínimo duas grandes virtudes: historicamente, ter percebido antes de qualquer outro a necessidade de renovar a literatura nacional, usando para tanto, ao lado da poesia, o teatro; esteticamente, ter tentado distinguir o drama romântico da tragédia clássica em nível de acuidade conceitual até então inédito em âmbito brasileiro.” (PRADO, 1996, p. 11)
}

E o finaliza dizendo: 
O que fica, no balanço derradeiro, é o seu papel de precursor, seja do romantismo, do qual foi meio sem o querer a ponta de lança no Brasil, seja, e aqui sem contestação possível, do próprio teatro nacional. Por ter escrito a primeira peça de valor do Brasil independente e por ter contribuído ativamente para o lançamento em alto nível de um ator como João Caetano, que dominará o palco e dará continuidade à atividade dramática nos decênios seguintes, merece o título, ambicionado e reivindicado por ele, de criador do teatro brasileiro moderno. (Idem, pp. 51-2)

O que dá a Gonçalves de Magalhães o lugar de "criador do teatro brasileiro moderno" é sua renovação estética à literatura dramática juntamente com a criação das condições de uma produção teatral nos moldes modernos. A primeira se dá exatamente na constituição de um Drama - mais especificamente drama romântico; e a segunda se dá na possibilidade da constituição de uma "continuidade à atividade dramática", através de João Caetano e da instituição de um "mercado" ${ }^{3}$ teatral no Brasil. A ideia de um mercado teatral é uma ideia claramente moderna, e num sentido específico marcará de forma muito precisa nosso teatro da primeira metade do século XX (BRANDÃO, 2002, p. 17) (inclusive nossos modernistas) e o pensamento de Décio.

Aqui se apresenta uma contradição importante, pois nos informa muito sobre nossos processos formativos ideológicos muitas vezes opostos a realidade material histórica, nossas “ideias fora do lugar”. Ao mesmo tempo em que certa lógica da formação de um mercado teatral nacional anima o pensamento formativo de Décio, há uma defesa de certo teatro sério, não muito afeito, na história do teatro, ao grande sucesso de público, que é herdada de nosso século XIX e seu projeto "civilizatório". A defesa do referido "teatro sério" encontra-se profundamente ligada ao projeto de constituição de uma nação civilizada e se expressa na crítica cultural numa divisão, mais ideológica do que estética, entre o tal "teatro sério" e o que se chamará de "teatro para rir" ou "teatro ligeiro". E assim como o projeto de constituição de uma nação civilizada (moderna) permanecerá ecoando no desenrolar do século XX, tal defesa também continuará a se fazer ouvir.

O pensamento de Décio de Almeida Prado não ficará imune à "contaminação" destes traços da visão modernista, não é à toa que em sua trilogia de obras históricas - $O$ teatro brasileiro moderno $(1988)^{4}$, Teatro de Anchieta a Alencar (1993) e O drama romântico brasileiro

\footnotetext{
${ }^{3}$ Décio não utiliza a noção de mercado, mas acreditamos que é o que se desenha em seu pensamento quando estabelece o papel de extrema importância de João Caetano na formação de nosso teatro moderno. Ver suas obras sobre o ator nacional João Caetano: o ator, o empresário, o repertório (1972) e João Caetano e a arte do ator: estudo de fontes (1984).

${ }^{4}$ Republicação ampliada de Teatro: 1930-1980 publicado em 1984.
} 
$(1996)^{5}$ - ao falar de Martins Pena, autor fundamental para formação de nosso teatro enquanto comediógrafo, Décio se limite a analisar alguns dramas praticamente desconhecidos e de nenhum sucesso do autor. Apostamos aqui que tais opções analíticas são, na verdade, impulsionadas pela ideologia nacionalista de um "projeto civilizatório" para o Brasil, empreendido pela intelectualidade brasileira do século XIX. Tal projeto, nascido do desejo de consolidação de uma sociedade brasileira moderna e civilizada (num modelo francês), a partir da consolidação de um Estado Democrático Moderno Liberal (República), é representado na produção teatral nacional pelo Realismo. Movimento que, tendo José de Alencar como um de seus grandes animadores, considerava o "teatro para rir" um gênero menor, precisando ser combatido ou reformulado. É famosa a proposta de José de Alencar de consolidação de uma "comédia séria" brasileira - expressa ao Sr. Dr. Francisco Otaviano, no Diário do Rio de Janeiro, em 1857, a propósito de sua peça $O$ demônio familiar, num texto muito apropriadamente chamado "A comédia brasileira" (ALENCAR, 2004, pp. 99-109) - buscando na França (civilizada), em Alexandre Dumas Filho, a forma enquanto modelo, porém com assunto nacional.

Ao analisar a obra de Alencar é exatamente isto que Décio procura: o que há de essencialmente e exclusivamente brasileiro nesta obra; e é exatamente sua capacidade de elaborar de forma própria as experiências externas (classicismo, romantismo e realismo) que expressa sua "brasilidade". Décio identifica o caráter que possibilita ao Demônio familiar de Alencar realizar-se como obra nacional "num certo adoçamento geral de todas as linhas". O que restaria da experiência realista é exatamente o trato ao cômico que aparece inserido no projeto civilizatório nacional: "Disfarçado em comédia, O demônio familiar é, na verdade, uma longa reflexão sobre a sociedade brasileira, com o fim de eliminar-lhe as contradições, de unificá-la socialmente e moralmente.” (PRADO, 1993a, p. 343). É exatamente essa visão tendente à certa "tradição do teatro sério" (civilizado, europeu, moderno) que oferece os pressupostos de definição ao segundo ponto de fraqueza na ideia de Formação que aparecerá no pensamento de Décio, ou seja, quais são os momentos decisivos e quais não são, e a partir de que pressupostos assim os julga?

O que se perceberá ao percorrer a história do teatro brasileiro escrita por Décio de Almeida Prado, da perspectiva da Formação do teatro nacional, é exatamente esse julgamento dos momentos decisivos numa perspectiva muito mais da formação de um teatro "moderno" brasileiro, e moderno nos moldes do teatro europeu (principalmente francês) Drama. Isso não é apenas uma exclusividade do crítico Décio de Almeida Prado, mas de

5 As datas referem-se às primeiras edições das obras citadas. A obra $O$ teatro brasileiro moderno é uma republicação ampliada da obra Teatro: 1930-1980, de 1984.

Berilo Nosella 
todo um pensamento sobre o teatro moderno brasileiro que se fincará nos horizontes de nossa historiografia, significando a exclusão de alguns momentos de nossa formação, talvez não tão interessantes para essa história. Apenas como exemplo, cito o teatro de tendências mais comerciais e cômicas, como o teatro de revista e o teatro ligeiro carioca; e o teatro amador anarquista, feito por imigrantes (principalmente italianos).

Numa breve conclusão, para que avancemos ao centro do artigo aqui proposto, poderíamos afirmar que o quadro aqui esboçado não apenas interfere na visão de Décio sobre a história passada do nosso teatro como na sua atividade como crítico. Justifica certa relutância de Décio, e de nossa crítica moderna, ao teatro épico, tanto de Brecht como de Piscator $^{6}$; e certos julgamentos dos principais fatos do teatro brasileiro do século XX como a supervalorização dos fenômenos Vestido de noiva (de Ziembinsk), do TBC e da EAD, por exemplo - novamente numa perspectiva de nascimento do teatro brasileiro moderno, e não do processo de constituição e continuidade de uma tradição tão caro ao pensamento sobre nossa Formação. Obviamente que esses impasses estarão entranhados na forma como foi compreendido e recebido por Décio um dos nossos dramaturgos modernos: Jorge Andrade; assim como um dramaturgo moderno estrangeiro, como Pirandello, foi aqui recebido pelo crítico.

\section{Pirandello e Jorge Andrade na crítica da formação do teatro brasileiro moderno}

A extensíssima obra crítica de Décio de Almeida Prado encontra-se publicada, a partir de seleção empreendida pelo próprio autor, em três volumes: Apresentação do teatro brasileiro moderno: crítica teatral de 1947-1955 (1956)7, Teatro em progresso: crítica teatral, 1955-1964 (1964) e Exercício findo: crítica teatral (1964-1968) (1987).

O primeiro volume, que nos parece fundamental para compreender o conjunto como uma "consciência" da formação teatral nacional, é organizado por Décio em cinco partes: Autores nacionais; Companhias nacionais; Teatro Brasileiro de Comédia; Temporadas estrangeiras; e Crônicas.

1) "Autores nacionais" é de uma coletânea de críticas que foca a produção dramatúrgica do período. Mesmo tratando-se de críticas a partir das montagens destes textos, o critério de agrupamento é a produção dramática literária. O referido bloco percorre de Vestido de noiva, de Nelson Rodrigues, encenada em 1943, à Moratória, de Jorge Andrade, encenada em 1955. A este bloco poderíamos chamar de "Ciclo de Formação do

\footnotetext{
${ }^{6} \operatorname{Ver}$ A resistência da crítica ao teatro épico (COSTA, 1998, pp. 75-102).

7 As datas aqui indicadas referem-se ao ano da primeira publicação, além destas, para a pesquisa, também foram utilizadas as edições recentes das mesmas 2001, 2002 e 2011, respectivamente.
} 
Teatro Brasileiro Moderno", o que já lança de início duas perspectivas: a primeira, a de um projeto de compreender e analisar um momento crucial, no entendimento do crítico, em que o referido teatro moderno "se forma" (obviamente, há no gesto intelectual do crítico o chamado de atenção e o desejo de colaborar com seu instrumental para que tal fato nascente se consolide). A segunda perspectiva vislumbra a percepção de que tal processo de formação baseia-se na necessária transformação e consolidação da produção dramatúrgica.

2) "Companhias nacionais" traça mais ou menos um mesmo percurso, porém tendo como critério de agrupamento as companhias teatrais nacionais que se formam e desenvolvem-se no período. O bloco inicia-se com Os Comediantes (responsáveis pela primeira montagem de Vestido de noiva) e termina com a Cia. Bibi Ferreira - passando pela EAD, o nascente Teatro de Arena e a Cia. Maria Della Costa (responsável pela primeira montagem de $A$ moratória). O que nos parece intrigante na seleção empreendida por Décio é primeiro a percepção do crítico de que se a formação de um teatro moderno passa necessariamente pelo desenvolvimento de uma dramaturgia moderna, ela não poderá ocorrer se a cena não for também moderna; e em segundo, como, apesar da correlação, que hoje nos parece óbvia, entre o trajeto da dramaturgia e da cena, esta última não é aqui contemplada. A análise de Os Comediantes é proposta a partir da crítica de sua montagem de Desejo, de Eugene O’Neil; e a da Cia. Maria Della Costa, pela crítica de O canto da cotovia, de Jean Anouilh. Parece-nos que Décio está aqui reforçando sua premissa de que a modernidade da cena precisa da modernidade da dramaturgia, a qual, no caso, ainda não temos no Brasil; por isso a importância da dramaturgia moderna "de fora" para empreender nossa “formação do teatro moderno brasileiro". Mostrando-nos que tal não é apenas uma suposição nossa, Décio declara na Introdução ao volume:

Em relação aos autores nacionais, cometo a heresia de pensar que, considerados em bloco, alguma coisa ainda os separa do nível já alcançado pelos nossos melhores atores, cenógrafos e encenadores, fato, entretanto, perfeitamente normal: no teatro, a revolução literária, sendo a mais profunda, é sempre a última a se fazer. O teatro, como o cinema, não depende só de inspiração mas de um conhecimento técnico que não se adquire sem uma certa íntima convivência. Para se escrever bom teatro, é necessário nascer e crescer dentro do bom teatro, recebendo as primeiras lições e as primeiras influências na idade em que se deve recebê-las: na adolescência. A esse respeito, estamos talvez em situação idêntica a dos Estados Unidos, nas vésperas do aparecimento de Eugene O’Neill. O instrumento já existe: precisa surgir quem saiba manejá-lo com técnica e originalidade. Então existirá, na verdade, um teatro brasileiro. (PRADO, 2001b, p. XXI) 
Por mais que tal pareça estranho ao movimento geral de modernização teatral, que historicamente nasce de par com a modernização literária, na verdade o que Décio crê, e aqui demonstra em sua organização, é exatamente isto: o teatro brasileiro, para se modernizar, precisa da dramaturgia moderna, porém, esta não é produzida aqui, então temos que trazê-la de fora. É perfeitamente claro a abertura do bloco com Os Comediantes encenando O’Neill. O que talvez ainda não salte aos olhos do crítico é o papel, também estrangeiro, interno à cena, empreendido pelos diretores, inclusive na percepção e revelação de que sim, há dramaturgia moderna e de qualidade feita no Brasil. A questão seria qual, ou mais além, o que seria uma dramaturgia moderna de qualidade?

3) Em "Teatro Brasileiro de Comédia”, como não poderia deixar de ser, mesmo tratando-se de uma "Companhia nacional", Décio reserva um capítulo à parte ao TBC, momento em que a modernidade realizar-se-ia em sua plenitude: dramaturgia moderna (ainda estrangeira) + cena moderna (tanto no que diz respeito a sua configuração estética: atores, direção, cenografia, etc; quanto no que diz respeito à organização e produção mercantil da mesma).

4) "Temporadas estrangeiras", Décio reúne aqui um conjunto de textos sobre a visita de duas Companhias estrangeiras (J.-L. Barrault e a Comédie Française) consideradas, segundo o crítico, como fundamentais no estabelecimento de um referencial de formação moderna para o teatro brasileiro, bem no sentido apontado por ele de uma espécie de "ambiente" propício onde o teatro brasileiro, “adolescente”, pudesse crescer e amadurecer bem.

5) "Crônicas", o último bloco, reúne algumas crônicas do período sobre personalidades ou montagens importantes da época, sempre no sentido de captar e consolidar o momento como um momento de formação, fecundação do moderno no teatro nacional.

O que nos fica muito forte do conjunto aqui apresentado é esse caráter programático da atividade crítica de Décio, que vem herdada de sua prática anterior na Revista Clima ${ }^{8}$, de uma militância pró-formação do teatro moderno nacional. Disto, o que nos interessará aqui, de imediato, é primeiro o papel que a dramaturgia de Pirandello terá neste programa (constam deste volume três críticas a peças do autor italiano) e em segundo, a centralidade que a peça $A$ moratória assumirá na compreensão e julgamento de todo o restante da obra de Jorge Andrade e, coerentemente, de todo teatro nacional

\footnotetext{
${ }^{8}$ Basta lembrarmos um par de críticas do período que já explicitam no próprio título esse caráter de apresentação quase didática do que é e do que deve ser o teatro moderno: "A convenção do teatro moderno I" (setembro de 1944) e "A convenção do teatro moderno II" (outubro de 1944).
} 
"moderno"; percebendo que há uma possível relação entre estes dois aspectos do pensamento crítico de Décio e que este aspecto nasce exatamente no denominado Ciclo da Formação do teatro brasileiro moderno (1947-1955), como "consciência do teatro moderno" brasileiro.

Há um aspecto central que parece saltar aos olhos ao lermos o conjunto de críticas de Décio a Pirandello e Jorge Andrade, para além da clara percepção da imensa admiração do crítico por ambos, que consiste no apontar do crítico a um elemento "humano" profundo presente na obra dos dois dramaturgos. Esse elemento "humano" configura-se como a presença de certa "qualidade de emoção" que em certos momentos apresenta-se como essência da brasilidade e em outros como uma qualidade do dramático que põe em cena personagens verdadeiramente humanas em oposição ao racionalismo épico, ou até mesmo, como um arrebatamento de entrega do público à fantasia e não a um debate conceitual de ideias. Defendemos aqui que tal percepção revela uma posição (consciente ou não) estético-política do crítico. Sua primeira crítica sobre Pirandello é uma crítica dupla, Décio analisa comparativamente duas montagens realizadas pela EAD em 1951 ${ }^{9}$, uma de Pirandello Um imbecil e uma de Brecht $A$ exceção e a regra. Algumas das ideias que se revelam neste texto perdurarão por quase toda atividade de Décio, a ponto de no último texto publicado sobre Pirandello, Pirandello: cem anos, de 1967, ainda o crítico as ter presente.

O que transparece ali é a clara oposição entre política e arte. Não se trata de afirmar que a arte não é política ou que não possa falar de política, por exemplo, mas sim de compreender que o nível estético deve vir em primeiro plano, a "qualidade artística" deverá apresentar-se como fim fundamental e único do teatro. Uma peça que tiver como propósito primevo a apresentação de ideias, teses, programas políticos, terá necessariamente sua "qualidade artística" diminuída. Assim ele percebe na comparação entre Um imbecil e $A$ exceşão e a regra.

Segundo o crítico, Pirandello traz a premissa de que a política desumaniza o homem, expressa através da personagem do militante socialista que é "burocratizado" pelo partido e perde sua humanidade; já Brecht, no jogo de revelação do absurdo entre exceção e regra, a partir da história do "empregado" humanizado que ajuda o patrão, demonstra que estamos todos desumanizados e a política é o caminho para a humanização. Acreditamos que há aqui um dado que nos parece ignorado: na peça Um imbecil, em específico, é obviamente a política partidária, mais especificamente a política partidária de esquerda, socialista, quem promove um processo de embrutecimento e desumanização

\footnotetext{
9 Trata-se da crítica De Pirandello à Brecht, publicada em Décio (2001, p. 140).
} 
necessário. Tal visada é contraposta por Décio à de Brecht em $A$ exceção e a regra uma vez que nesta, Brecht afirmaria exatamente o oposto. Para Pirandello a política promoveria a desumanização e para Brecht apenas ela poderia ainda promovê-la. O equívoco que nos parece ocorrer está na noção de política, não contextualizada historicamente. Pirandello está em sua obra falando claramente da política partidária sectária, e acredito que a história nos tenha dado provas suficientes da verdade da afirmação Pirandelliana. Talvez pudéssemos até radicalizar, dizendo que, em certo sentido, o próprio foi como "Un'imbecille" de seu tempo, não fosse sua obra para nos provar o contrário. Neste sentido, a obra de Pirandello, de 1922, não deixa de apresentar-se como crítica altamente pertinente a um processo histórico que ali se inicia onde um militante socialista, chamado Mussolini, levará tantos outros, como o próprio Pirandello, ao Fascismo ${ }^{10}$.

Já Brecht não está falando da mesma política, o sentido de política ou de ideologia comunista presente em Brecht, sabemos, transcende a filiação sectária ao Partido Comunista de Moscou, a quem, inclusive, Brecht não era filiado e nem por isso alguém poderá acusá-lo de não ser comunista. Aqui, nos parece, há um segundo equívoco do crítico, uma vez que no todo de sua obra, sua resistência à Brecht apresente-se como uma resistência ao comunismo. Novamente é preciso historicizar: entre 1940-1960, de onde fala nosso crítico, falar em comunismo era falar em Stalinismo. Nesta afirmação está presente um alinhamento da esquerda mundial e brasileira que se dividirá entre comunistas e socialistas, sendo os segundos ligados a uma corrente trotskista (anti stalinista). Não precisamos entrar no mérito da questão de forma minuciosa, mas tal ligação de Brecht ao comunismo stalinista já se mostrou equivocado em várias análises de suas obras. Não se trata de acusar Décio de uma falha imperdoável, sua historicidade é tão premente que um crítico e teórico da envergadura de Adorno também a cometeu ${ }^{11}$. Porém, acreditamos que este ponto não explique totalmente o olhar do crítico para Pirandello, afinal, como já questionou Iná Camargo Costa (1998, pp. 101-2), se ser comunista é motivo suficiente para certa desqualificação de Brecht por Décio, porque ser fascista não o é para Pirandello?

Apesar de a questão, como colocada por Iná, nos apontar uma polêmica fundamental, não acreditamos que ela chegue a uma resposta. Parece-nos que Iná apenas “inverte os

10 “Em L'imbecille está toda a italiazinha provincial já carregada daquele fervor partitocrático tão compacto e obtuso a ponto de produzir, em seguida, a semente obscura do fascismo. L'imbecille é uma amostra extraordinária da Itália que começa uma marcha para uma Roma sempre mais tétrica e é também um quadro convulso e paradoxal do faccioso partidarismo político que nos faz descobrir a baixeza do engano, a inversão do sentido da realidade. (Introdução a uma edição recente da peça L'Imbecille de Pirandello. Pirandello, 2007 in www.pirandelloweb.com) (tradução minha).

${ }^{11}$ Sobre o equívoco do stalinismo de Brecht e a sua polêmica com Adorno ver a tese de José Fernando Peixoto de Azevedo (2007), Brecht: experiência e engajamento. Uma leitura de A Medida, e Brecht, Adorno e o interesse do engajamento, de Iná Camargo Costa (1998, pp. 215-237). 
polos" do pensamento de Décio para lhe apontar uma fragilidade argumentativa na desqualificação de Brecht, mas não explica em verdade seu apreço por Pirandello. No fim, o que Iná faz é desqualificar Pirandello na mesma chave argumentativa que critica em Décio, não fazendo avançar o debate. Porém, ainda nos parece um ponto de partida válido, por apresentar um olhar interessado politicamente como contraponto ao olhar do crítico, que renega o político. Se podemos afirmar que a crítica de Iná ao dramaturgo italiano, baseada no fato de sua filiação partidária ao fascismo, não é suficiente, a de Décio, baseada num suposto apartidarismo de Pirandello também não o é.

Afirmamos que negar o fato histórico da filiação de Pirandello ao partido fascista, num ato de ignorar tal fato pela lente do apolítico, não nos ajuda a compreendê-lo. Mas também concordamos que é preciso compreender como e porque, historicamente, Décio "optou" por Pirandello. E achamos que tal só pode ser feito se procurarmos compreender o olhar de Décio no sentido da busca daquilo que nos é (ao menos em seu julgamento) de interesse. O que queremos dizer é que, na verdade, a atividade crítica de Décio busca em seu todo uma análise do teatro moderno interessado, no caso, na formação do teatro moderno brasileiro, ou seja, é preciso buscar nas obras modernas como um todo, sejam nacionais ou estrangeiras, aquilo que nos diz respeito, aquilo que nos apresenta caminhos pertinentes, aquilo que nos forma. Dizer isto é dizer que um autor como Pirandello, em última instância, interessa a Décio naquilo que ele interessa ao Brasil e ao teatro brasileiro. Décio não analisa, não critica Pirandello com um olhar universal, procurando compreendêlo em seus contextos próprios, italianos no caso, mas sim como um autor estrangeiro que se apresenta como fundamental para o processo de formação do teatro moderno brasileiro. E aqui retornamos à ideia da "qualidade de sentimento" humano. Pirandello, na visão do crítico, tem essa qualidade. Como vimos, tal qualidade vem do "adoçamento geral das linhas" (classicismo, romantismo e realismo) que privilegiaria a presença de um "sentimentalismo" romântico, ou poderíamos até dizer melodramático, característico de nossa forma de ver e sentir o mundo. Assim sendo, a forte oposição ao melodrama que o projeto épico propõe não "cai como uma luva" à visão de teatro moderno do crítico para o Brasil. Como percebe Sergio R. de Carvalho, é exatamente a forma pirandelliana de impor a crítica, de caráter profundamente modernista, ao melodrama sem descartar radicalmente seu espírito que provavelmente o torna "um emblema da dramaturgia moderna" para nós brasileiros (Santos, 2002, p. 54). Indo mais além, Sergio R. de Carvalho Santos nos revela que esta percepção não é novidade em Décio, mas está impregnada também em nosso modernismo, no pensamento de Alcântara Machado: 
Mais importante ainda era o caráter marginal da pesquisa formal de Pirandello em relação à tradição europeia realista da crise do drama. Aquilo que Alcântara Machado considerou como uma teatralidade "à margem de todos os tempos" pode ser lido como verificação de que Pirandello demonstrava ser praticável um caminho de modernização alternativo em relação à história do drama realista. Diversamente de outras tentativas épicas, como a dos autores franceses e alemães, a crítica de Pirandello não decorria do aprofundamento das contradições entre a forma dramática e a sondagem da realidade. Sua ultrapassagem fazia um salto direto do melodrama romântico para o vanguardismo literário. (SANTOS, 2002, p. 56)

Perceber essa forma de entender Pirandello, afastado de seus elementos realistas, como uma solução alternativa à experiência naturalista europeia do fim do século XIX ${ }^{12}$, que na verdade opõe-se, por exemplo, à maneira como um crítico francês brechtiano como Bernard Dort ${ }^{13}$ o fez, é fundamental para entendermos como Décio irá perceber a obra de Jorge Andrade, tendo A moratória como paradigma e com claro declínio de seu "valor artístico" quanto mais sua obra se aproximar da experiência histórica nacional.

Como dissemos, e isso persiste em todas as críticas de Décio às obras de Jorge Andrade, o comparativismo com $A$ moratória, sempre insuperável, é o elemento central de julgamento do crítico. Não é o caso de citarmos uma a uma as mesmas, mas basta que se passe o olho sobre elas e isso é facilmente identificável: A moratória é, de uma forma ou outra, sempre citada no conjunto de críticas às obras de Jorge Andrade. Seja num sentido valorativo, onde se confirma e reforça a preferência de Décio pela obra, como por exemplo na crítica à Pedreira das almas de 1958:

Se nos obrigassem a escolher entre as duas peças, não hesitaríamos em ficar com $A$ Moratória. As qualidades de Jorge Andrade, se não estamos enganados, são antes dramáticas do que literárias.

(...)

\footnotetext{
12 "A esperança talvez fosse de que o modernismo teatral brasileiro poderia também saltar a vertente realista, cuja carência parecia marcar não só o teatro italiano e espanhol, mas o de todos os países em que a ideologia da mobilidade social mantinha pouco vínculo com as práticas sociais.

Não por acaso, foram locais de maior duração dos padrões populistas de uma teatralidade que, mantendo o discurso da liberdade, se servia dos padrões emocionalistas do início da dramaticidade burguesa, com 'tudo que agradava o público - melodrama, sensacionalismo, retórica, e intensa teatralidade’.” (SANTOS, 2002, p. 56)

13 Bernard Dort, em seu artigo "Pirandello e o teatro francês" (1977, pp. 193-220) aponta como equivocado o caminho tomado por certos diretores de seu país em supervalorizar o que ele chama de pirandellismo, que seria exatamente os aspectos formais ligados ao jogo metateatral e de exaltação do universo fantasioso em detrimento dos aspectos naturalistas, mais ligados à realidade, presentes no dramaturgo. Segundo o crítico, tal "equívoco" que teria suas bases nas montagens de Copeau, na década de 1920, buscando no dramaturgo a "ruptura com o naturalismo" (DORT, 1977, pp. 197-8) e só seria superada em montagens do dramaturgo pós- $2^{a}$ Guerra Mundial, quando a partir de montagens de jovens diretores franceses "uma nova imagem de Pirandello se delineia: um Pirandello realista” (Idem, p. 200).
} 
Já Pedreira das Almas é uma tentativa literária mais ousada: muitas de suas situações desejam viver principalmente do prestígio épico ou lírico das palavras. São, ao nosso modo de ver, as mais fracas. (PRADO, 2002, p. 108)

Seja simplesmente tendo a obra como referencial comparativo de análise, onde Décio mediria o "grau de afetividade" do dramaturgo presente nas obras. A moratória serviria como uma espécie de termômetro das outras obras, um bom exemplo disso se dá na crítica de $A$ escada de 1961:

Não são poucos os temas de $A$ Moratória que aparecem em $A$ escada, porém modulados de outra forma (...).

(...)

O laço que liga autor e personagens, em A Moratória, é fortemente afetivo: sentimos que o criador ama as suas criaturas, desculpando-as ao mesmo tempo em que as desaprova. O clima é intimista, melancólico, de secreta ternura, de infindável sondagem psicológica. São apenas seis personagens que Jorge Andrade vira e revira amorosamente entre os dedos. Já em $A$ escada não existe esta cumplicidade, esta compreensão profunda. O corte é outro, antes horizontal do que vertical, apanhando um número enorme de pessoas que são caracterizadas em traços enérgicos, por contrastes violentos, sem demoras introspectivas. A peça entrega-se ao público sem reservas ou pudores, sem zonas de silêncio ou obscuridade. Não que a agudeza psicológica seja menor, mas o olhar do autor se aplica, objetivamente, vendo as pessoas de fora para dentro. (Idem, pp. 220-22)

No conjunto, de uma forma ou de outra, fica claro que para Décio $A$ moratória é a maior e melhor obra de Jorge Andrade e o grande feito de nossa dramaturgia moderna. Não é à toa que ele fecha o primeiro capítulo de Apresentação do teatro brasileiro moderno, aquele que chamamos de Ciclo da Formação, que se debruça sobre a dramaturgia nacional, com a crítica a essa peça na montagem de 1955 pela Cia. Maria Della Costa, dirigida por Gianni Ratto. Ali o ciclo se fecha com A moratória; o Ciclo de Formação se completa. E a razão fundamental da grandiosidade desta obra para nós, brasileiros, é exatamente sua "qualidade de emoção" - captada pelo crítico em O demônio familiar e presente também em Pirandello e na dramaturgia ibérica - mais próxima do romantismo que do naturalismo.

Quanto ao resto, que é tudo, não há peça nenhuma mais genuinamente brasileira do que a de Jorge Andrade. Brasileira, de início, está claro, pelo quadro social. A Moratória mantém-se quase exclusivamente no plano psicológico, evitando o pitoresco fácil: não é, certamente, um drama rústico, recheado de cor local.

(...)

Mas o seu verdadeiro brasileirismo não é exterior, não está no cenário, na descrição superficial de certos hábitos e modismos regionais. Brasileira parece-nos a própria qualidade de sua emoção. A literatura europeia moderna, como se sabe, baniu o sentimento: Kafka descreve pesadelos mas não perde jamais o tom seco, nítido, cortante. Uma lágrima autêntica, não filtrada pela estética, isenta de ironia ou sarcasmo, causaria pasmo no teatro francês atual: dir-se-ia termos voltado ao melodrama e ao burguês século dezenove. Somente os italianos (veja-se o neo- 
realismo cinematográfico) ousam de vez em quando aproximar-se do sentimentalismo, e assim mesmo com que preocupações (PRADO, 2001b, p. 9798).

Tal posição desdobra-se num olhar sobre a obra de Jorge Andrade, onde as estruturas dramáticas, que oporiam sentimento x razão, verdade humana x categorização social das personagens, guiarão o crítico no julgamento a cada uma das futuras obras do dramaturgo. É importante frisar aqui que em vários momentos Décio irá criticar, principalmente nas opções cênicas dos diretores que trabalharão com Jorge, certa falta de naturalidade das personagens, não se trata de forma alguma de naturalidade no sentido naturalista apenas, mas sim de uma verossimilhança psicológica que se aprofundaria para além de certa tipologia social, própria de um movimento como o naturalismo e do teatro épico, responsável por trazer à cena a questão social de classe como elemento primeiro de construção cênica e das personagens. Como se perceberá na crítica à encenação de Pedreira das almas, pelo TBC em 1958, dirigida por Alberto D’Averssa:

A encenação tem, contudo, os defeitos de suas qualidades. Tendendo para o heroico, nem sempre foge a certo formalismo, a certo hieratismo que deixa de humanizar o texto. A representação não cresce, não tem momentos de repouso: mantém-se de princípio ao fim no auge da intensidade. Os atores, com a consciência de enfrentar um texto de valor incomum, não afrouxam a tensão, não ousam se mostrar mais naturais. (Idem, p. 109)

Também é interessante, neste sentido, notar como certas soluções tendentes ao cômico, em obras como $A$ escada ou Os ossos do barão, também apresentam restrição por parte do crítico, se não tanto pela comicidade apenas, mas pelo "esquematismo social" que a estrutura cômica permite. No caso de Ossos do barão, por exemplo, o crítico afirmará que "pesam também sobre a peça as suas intenções sociais". (Idem, p. 257). Na crítica à Escada, por exemplo, em explícita comparação $\operatorname{com} A$ moratória, o crítico aponta a razão de certas "falhas" da peça (já apontadas aqui como esquematismo social interligado à estrutura cômica, farsesca da peça) pela "distância" da temática urbana que aparece como novidade naquele momento da obra de Jorge Andrade com a realidade do autor, o que prejudicaria a "qualidade da emoção" da mesma.

Acreditamos que a análise deste quadro da crítica de Décio de Almeida Prado nos esclareça um pouco o traçado da relação de julgamento do crítico com a obra de Jorge Andrade num contexto mais amplo da compreensão do projeto, do crítico, de formação do teatro brasileiro moderno. Neste contexto, Jorge Andrade apresenta-se com autor de suma importância para Décio, pois é ele o autor que carregará consigo a herança de tal linhagem 
teórica e ideológica. Como grande dramaturgo brasileiro, como aluno de Décio na Escola de Arte Dramática ${ }^{14}$ e como parte de uma geração que carregou tal projeto como grande empreitada teórica. A referida herança nos parece transparecer claramente no próprio projeto dramatúrgico de Jorge no ciclo Marta, a árvore e o relógio, com suas dez peças que percorrem a história de nosso país, mas na visão de Décio, como estamos verificando, se perde, no decorrer da produção da referida obra, no elemento formal. Conforme Jorge Andrade caminha com sua obra em direção ao presente, à política e às estruturas épicas e metateatrais, Décio vê cada vez com mais dureza e ressalvas sua obra. Porém, o contrário ocorre com a metateatralidade pirandelliana. Acreditamos, e procuramos minimamente demonstrar aqui, que tal se dê, pois o olhar do crítico para a obra de Pirandello permanece num nível apenas formal, não se aprofundando historicamente, não procurando compreender o que (como e porque) o dramaturgo significa para a formação especificamente italiana e as suas relações com o contexto político e econômico do país na década de 1920 e início de 1930. Não se trata de uma simples crítica a Décio, que tem sua atitude perfeitamente justificada pelo olhar interessado no Brasil e na formação do teatro brasileiro, mas sim de compreender como o crítico recebe de formas tão diversas manifestações próximas do épico no teatro moderno. A posição final do crítico de ressalva à "epicização", rumo a uma maior politização, da obra de Jorge Andrade se expressa exatamente em sua obra $O$ teatro brasileiro moderno, numa expressão crítica às duas últimas peças metateatrais do dramaturgo: As confrarias e $O$ sumidouro:

A ruptura com o realismo, contudo, só se consuma no fecho do ciclo, com $O$ sumidouro e As confrarias. Enquanto metateatro, ambas as peças falam sobre o teatro, como um espelho que refletisse também a si mesmo e não apenas a realidade. E enquanto textos épicos, ou epicizantes, não vacilam, mormente o primeiro, em aproveitar os mais modernos recursos cenográficos, como preconizava Piscator: projeção de slides, de filmes, de tudo o que faça o palco narrar, completando a ação. Jorge Andrade, se não se convertera ao brechtianismo, já não podia dar-se o luxo de ignorar as vantagens oferecidas por um sistema que permite discutir, por sobre as querelas individuais, as grandes questões históricas. Aos poucos, o social suplanta o psicológico, o teatro político impusera-se ao realista, dando a última palavra (através de Marta) ao povo, e não aos fazendeiros mineiros ou aos aristocratas mais urbanizados de São Paulo.

Resta saber se o escritor paulista não se prejudicou um pouco com essa evolução. As últimas peças do ciclo envolvem projetos tão grandiosos, pedem número tão grande de atores e tal aparato cênico, que deixaram de ser representáveis, pelo menos de momento, por um teatro pobre como o nosso. De outra parte, ele sobrecarregou tanto o texto de segundas intensões, de alusões mais ou menos recônditas, de informações dadas de raspão, obliquamente, que é o caso de se perguntar - só a representação nos daria a resposta - se não comprometeu às

${ }^{14}$ Também parte fundamental do referido projeto de formação. 
vezes o essencial, obscurecendo a linha de desenvolvimento do enredo. (PRADO, 2001a, p. 96)

Na presente passagem fica claro o sentimento de "desconfiança" de Décio, mesmo em suspenso pela falta da representação, pelos caminhos trilhados por Jorge Andrade. Tal "desconfiança”, gerada pela própria radicalização no sentido da modernidade cênica assumida pelo dramaturgo no desenvolvimento do ciclo, pode parecer incoerente num crítico tão preocupado com a consolidação e divulgação do teatro moderno entre nós. $\mathrm{O}$ que tentamos aqui foi exatamente demonstrar que não é, pois possui justificativas profundas no pensamento de Décio (e de uma longa tradição do pensamento cultural brasileiro), mas que precisa ser revisto de forma pertinente para que nos compreendamos como críticos, criadores e pensadores das artes teatrais brasileiras.

\section{BIBLIOGRAFIA CITADA:}

AGUIAR, Flávio. A dor e o júbilo: Artur Azevedo e a formação da dramaturgia brasileira. In: Sala Preta: Revista do departamento de artes cênicas. no. 3 ECA-USP, 2003.

ALENCAR, José. Comédias. São Paulo, Martins Fontes, 2004.

ANDRADE, Jorge. Marta, a árvore e o relógio. São Paulo, Perspectiva, 2007.

AZEVEDO, José Fernando Peixoto de. Brecht: experiência e engajamento. Uma leitura de A Medida. 2007. Tese (Doutorado em Filosofia). São Paulo, USP/FFLCH.

BERNSTEIN, Ana. A crítica cúmplice: Décio de Almeida Prado e a formação do teatro brasileiro moderno. São Paulo, Instituto Moreira Salles, 2005.

BRANDÃO, Tânia (org.). A máquina de repetir e a fábrica de estrelas: Teatro dos Sete. Rio de Janeiro, 7letras, 2002.

CANDIDO, Antonio. Formação da literatura brasileira: momentos decisivos 1750-1880. $10^{\mathrm{a}}$ ed. Rio de Janeiro, Ouro sobre Azul, 2006.

CHIARADIA, Maria Filomena Vilela. A companbia de revistas e burletas do Teatro São José: a meninados-olhos de Paschoal Segreto. 1997. Dissertação (Mestrado em Artes Cênicas). Rio de Janeiro, UNIRIO.

COSTA, Iná Camargo. Sinta o drama. Petrópolis, RJ, Vozes, 1998.

DORT, Bernard. O teatro e sua realidade. São Paulo, Perspectiva, 1977.

GUINSBURG, Jacó. Stanisláuski, Meierbold \& cia. São Paulo, Perspectiva, 2008.

MATTOS, David José Lessa. O espetáculo da cultura paulista: teatro e televisão em São Paulo (19401950). São Paulo, Códex, 2002.

PRADO, Décio de Almeida. Teatro em progresso: Crítica Teatral de 1955-1964. São Paulo, Perspectiva, 2002.

. O teatro brasileiro moderno. 2. ed. São Paulo, Perspectiva, 2001a.

$2001 \mathrm{~b}$ - Apresentação do teatro brasileiro moderno: crítica teatral de 1947-1955. São Paulo, Perspectiva,

_. O drama romântico brasileiro. São Paulo, Perspectiva, 1996.

. Teatro de Anchieta a Alencar. São Paulo, Perspectiva, 1993.

. Exercício findo: crítica teatral de 1964-1968. São Paulo, Perspectiva, 1987.

ROSENFELD, Anatol. Visão do ciclo. In: ANDRADE, Jorge. Marta, a árvore e o relógio. São Paulo, Perspectiva, 2007.

SANTOS, Sérgio Ricardo de Carvalho. O drama impossivel: teatro modernista de Alcântara Machado, Oswald de Andrade e Mário de Andrade. 2002. Tese (Doutorado em Literatura Brasileira)São Paulo, $\mathrm{USP} / \mathrm{FFLCH}$. 
SCHWARZ, Roberto. Cultura e política. São Paulo, Paz e Terra, 2001.

Abstract: The present work stand as an exercise in an attempt of pointing out some fundamental issues of Décio de Almeida Prado's thoughts in which regards the formation of the Brazilian modern theater. Examining how did Décio hinged, in his critical activity, a reception of Luigi Pirandello and Jorge Andrade's into our stages.

Keywords: Décio de Almeida Prado; brazilian modern theater; modern cultural formation. 